\title{
Nonlinear Analysis of Bending GFRP Tube Concrete Member
}

\author{
Cheng Fan, Jiaxiang Wang, Zhigang Song \\ Research Center for Numerical Tests on Material Failure, Dalian University, Dalian 116622, \\ China \\ E-mail: fancheng@dlu.edu.cn
}

\begin{abstract}
In order to study the factors that influence anti-bending mechanical properties of GFRP tube confined concrete beams and better applied to engineering, the influence of different thickness of GFRP tube, concrete strength grade, the section form and strength of steel were analyzed using finite element analysis software ABAQUS when the beam is in compression condition in this paper. The results showed that the bearing capacity of beams was improved by increasing the GFRP tube thickness, improving the core concrete strength and increasing steel area and strength. The numerical results were in good agreement with the experimental one. The anti-bending bearing capacity formula was in good agreement with the experimental results.
\end{abstract}

Keywords: GFRP tube; ABAQUS; mechanical property; the bearing capacity.

\section{Introduction}

The compression member's constraint effect of GFRP tube on the core concrete was better than that of the bending, but it was more common that the GFRP concrete composite components bear the bending moment in actual construction, such as large eccentric compression components, small eccentric compression members and tension-flexure components were not only to bear the axial force but also to bear the bending moment $[1,2]$. Therefore, it is necessary to study the flexural properties of GFRP confined concrete members[3, 4].

In this paper, the existing test results was simulated using the finite element software ABAQUS. Based on the facts that the numerical results were in good agreement with the experimental one, the influence of different thickness of GFRP tube, concrete strength grade, the section form and strength of steel when the beam under the compression were analyzed.

\section{Finite element basis}

\subsection{Concrete constitutive equations}

By verified a large number of numerical results, the constitutive relation of core concrete used the concrete constitutive relation model of Zhao et al [5], and the expression is given as:

$$
\sigma_{\mathrm{c}}=\left\{\begin{array}{cc}
\sigma_{0}\left[\mathrm{~A}\left(\frac{\varepsilon}{\varepsilon_{0}}\right)-\mathrm{B}\left(\frac{\varepsilon}{\varepsilon_{0}}\right)^{2}\right] & \left(\varepsilon \leq \varepsilon_{0}\right) \\
\sigma_{0}(1-\mathrm{q})+\sigma_{0} \mathrm{q}\left(\frac{\varepsilon}{\varepsilon_{0}}\right)^{0.1 \theta^{\prime}} & \theta \geq 1.12\left(\varepsilon \leq \varepsilon_{0}\right) \\
\sigma_{0} \frac{\varepsilon}{\varepsilon_{0}}\left[1 / \beta\left(\frac{\varepsilon}{\varepsilon_{0}}-1\right)^{2}+\frac{\varepsilon}{\varepsilon_{0}}\right] & \theta \geq 1.12\left(\varepsilon \leq \varepsilon_{0}\right)
\end{array}\right.
$$

The calculation of the relevant parameters is referred to [5].The tensile stress relationship model of concrete is given as:

$$
\sigma_{\mathrm{t}}= \begin{cases}\left(1.2 x-0.2 x^{6}\right) \sigma_{\mathrm{p}} & \varepsilon \leq \varepsilon_{\mathrm{p}} \\ \frac{x}{0.31 \sigma_{\mathrm{p}}(x-1)^{1.7}+x} & \varepsilon \leq \varepsilon_{\mathrm{p}}\end{cases}
$$

Where, $\sigma_{\mathrm{p}}$ means peak stress, $\sigma_{\mathrm{p}}=0.26\left(\mathrm{f}_{\mathrm{cu}}\right)^{2 / 3}, \varepsilon_{\mathrm{p}}$ means peak strain, $\varepsilon_{\mathrm{p}}=43.1 \sigma_{\mathrm{p}}(\mu \varepsilon)$.

\subsection{Constitutive model of GFRP tube}

The mechanical properties of GFRP tube (Fig.1) on the elastic section was simulated using ABAQUS singlelayer plate model, and the Hashin failure criteria[6] was used in ABAQUS to approximate simulate the composite material's damage evolution process. The correlation parameters of single layer plate was calculated using the analytical method in the mesomechanics of the composite materials[7]. Then a pavement design about GFRP tube was provided, for example, pavement design to $6 \mathrm{~mm}$ thick GFRP tube (Table 1). 


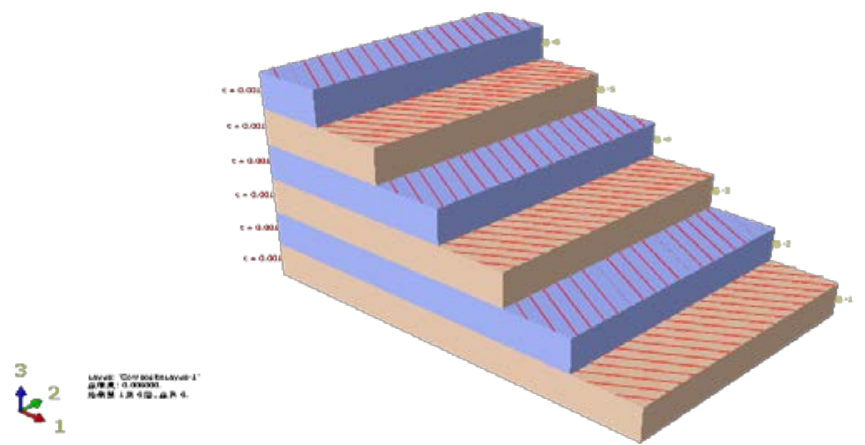

Fig. 1 GFRP tube paving method

Table $16 \mathrm{~mm}$ GFRP tube paving situation

\begin{tabular}{clcccccc}
\hline $\begin{array}{c}\text { Total } \\
\text { thickness }\end{array}$ & \multicolumn{7}{c}{ Pavement design } \\
\hline \multirow{2}{*}{$6 \mathrm{~mm}$} & Single layer angle & 30 & -30 & 30 & -30 & 30 & -30 \\
& Single layer thickness & 0.001 & 0.001 & 0.001 & 0.001 & 0.001 & 0.001 \\
\hline
\end{tabular}

\subsection{Establishment the finite element model}

In order to improve the efficiency of numerical calculation, $1 / 2$ model was taken to be calculated, applying the symmetrical constraint about $\mathrm{Z}$ axis on the mid-span, the concrete and the pad were using eight-node hexahedral reduction integral unit (C3D8R), the steel and GFRP tubes were modeled by using the shell element S4R (four-node reduction integral), in the thickness direction. Fig.2 shows the use of three integral points Poisson integral, the various parts of the finite element model and boundary conditions.
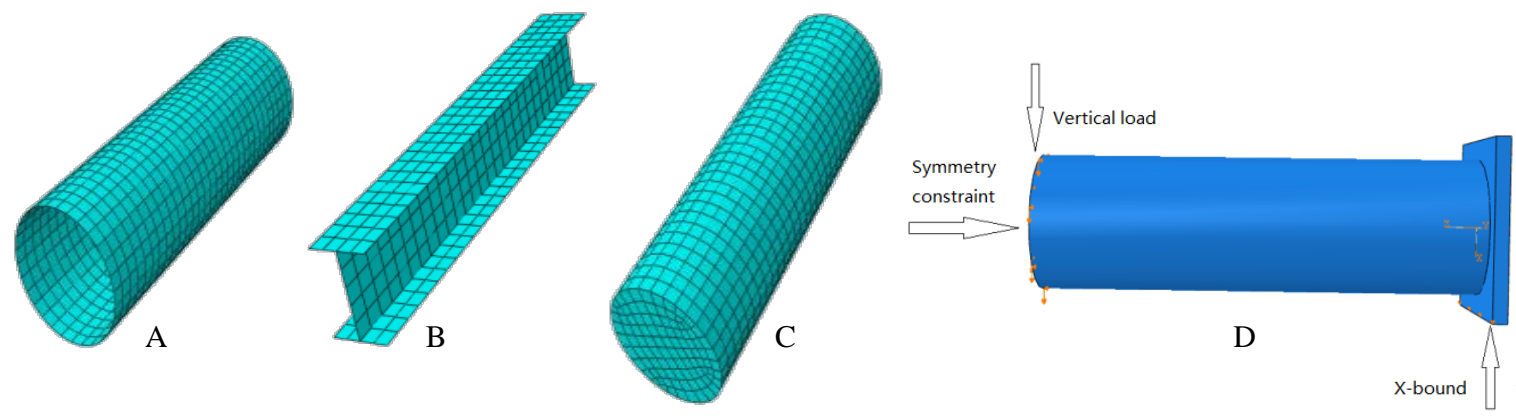

Fig.2Each part of the component model boundary and the meshing A) GFRP tube; B) Steel bone; C) Concrete and D) Boundary and load conditions

\section{Experimental verification}

In order to verify the accuracy of the numerical model, the numerical simulation in the bearing capacity was

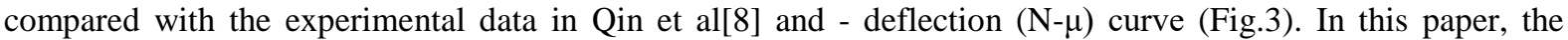
detailed experimental data and the bearing capacity calculated one compared with the experimental data in Table 2.

Table2 and Fig. 3 shows that the numerical simulation was in good agreement with the experimental data, and the calculation curve were under the experimental curve, the calculation ware safe and the model accuracy was verified. 
Table 2 Detailed data

\begin{tabular}{lllrrrrr}
\hline $\begin{array}{l}\text { Specimen } \\
\text { number }\end{array}$ & $\mathrm{L}(\mathrm{mm})$ & $\mathrm{D}(\mathrm{mm})$ & $\mathrm{F}_{\mathrm{c}}(\mathrm{MPa})$ & $\begin{array}{c}\text { Fiber } \\
\text { winding angle }\end{array}$ & $\mathrm{N}_{\text {exp }}$ & $\mathrm{N}_{\text {cal }}$ & $\mathrm{N}_{\text {exp }} / \mathrm{N}_{\text {cal }}$ \\
\hline WGSC1 & 1200 & 200 & 48.6 & 80 & 177 & 187 & 0.95 \\
WGSC2 & 1200 & 200 & 48.6 & 60 & 201 & 202 & 0.99 \\
WGSC3 & 1200 & 200 & 48.6 & 60 & 185 & 186 & 0.99 \\
\hline
\end{tabular}
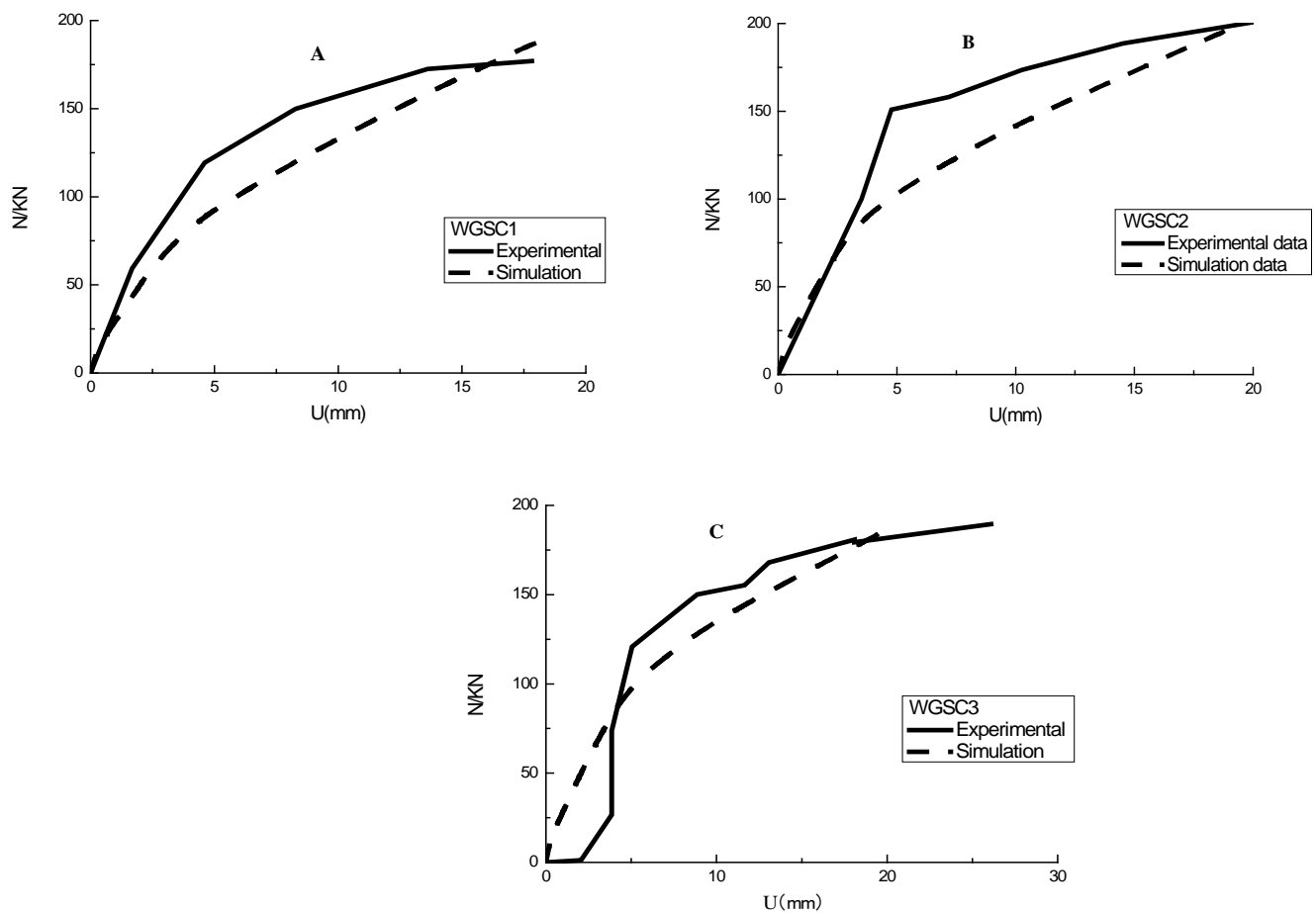

Fig.3 Experimental Curve Compared with Simulation Curve A) WGSC1; B) WGSC2 and C) WGSC3

\section{Analysis of influencing factors of $M-\mu$ curve}

The factors affecting the component's bending properties were the fiber winding angle of the GFRP tube, the wall thickness of the GFRP tube, the strength grade of the concrete, the cross section and the strength of the steel. Based on the accuracy of the simulation model to design specimen, the above factors were investigated using the finite element software.

\subsection{The effect of fiber winding angle}

Fig.4(1) shows the effect of fiber winding angle; it can be seen from the $\mathrm{M}-\mu$ curve that fiber winding angle has less influence on the early loading, because the lateral expansion of the concrete were not obvious at this time, and the constraint effect of the GFRP tube was not obvious too. The deflection of the concrete was all small. As the load increased, the steel and the GFRP tube emerged the confining effect, and the increasing of the component's deflection became slow. The larger the fiber winding angle was, the stronger the bending resistance of the concrete would be. Fig. 4(2) shows with the increasing of the fiber winding angle, bending bearing capacity have an approximate linear growth.

\subsection{Effect of steel type}

Fig. 5(1) shows the effect of steel cross section. The M- $\mu$ curve showed that with the steel type change, the structure' initial stiffness enhanced along with the steel cross-sectional area's increased, elasticity segment increased, and the slope of the elastic section on $\mathrm{M}-\mu$ curve became larger, the component bending capacity greatly enhanced. Fig. 5(2) shows with the increasing of steel cross-sectional area, bending capacity have an approximation parabolic growth. 

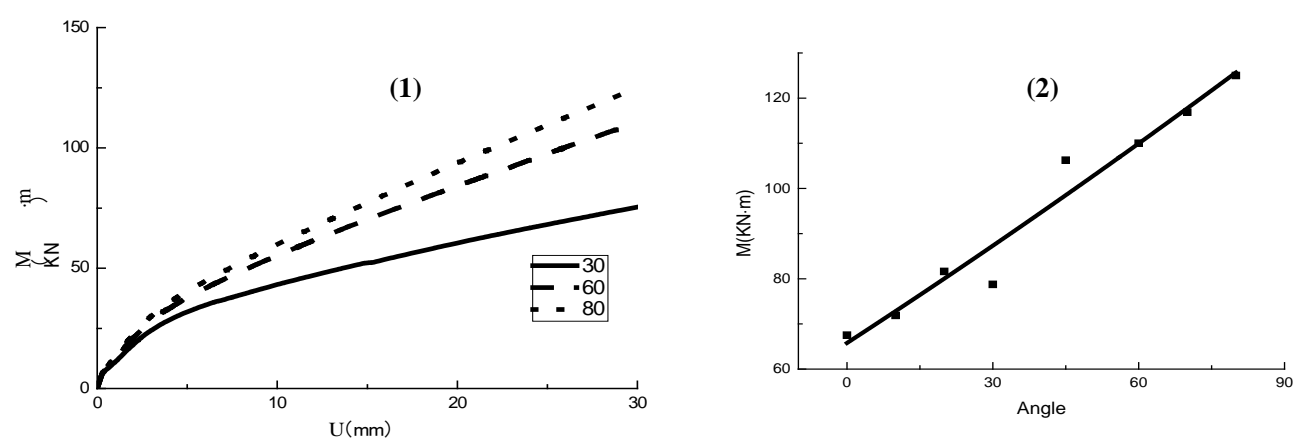

Fig. 4 Numerical simulation curve (Effect of fiber winding angle)
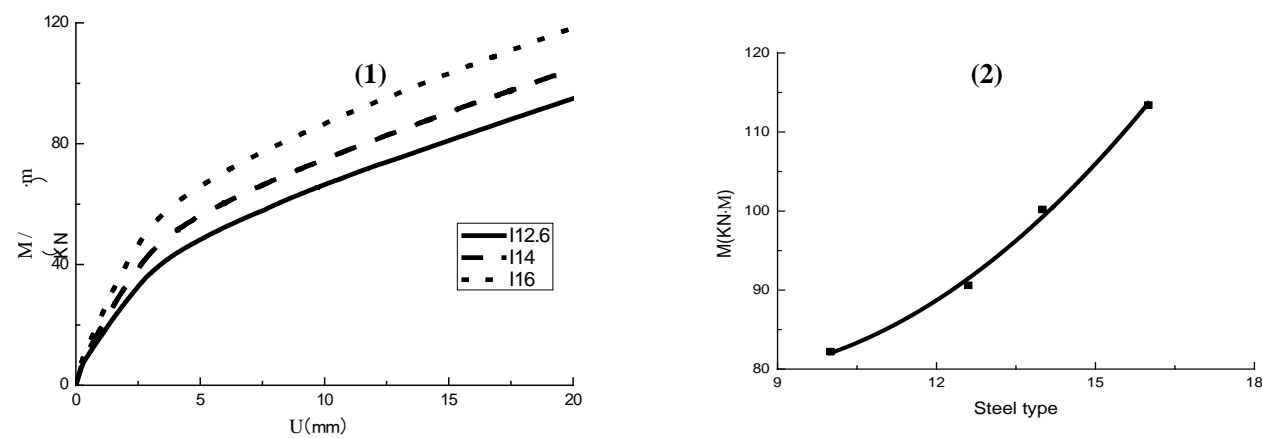

Fig.5 Numerical simulation curve (effect of steel type)

\subsection{Effect of concrete strength}

Fig.6(1) shows the effect of concrete strength grade. Concrete was a brittle material, the concrete reached the tensile strength limit because of the load which was perpendicular to the cross section quickly at the elastic phase, and then the concrete tension zone quit of the job, so the deflection was very closed to the other, we can obtain a conclusion that the concrete strength grade has little effect on the bending capacity of the composite members Fig.6(2). The bending capacity has a little growth along with the concrete strength grade increase.
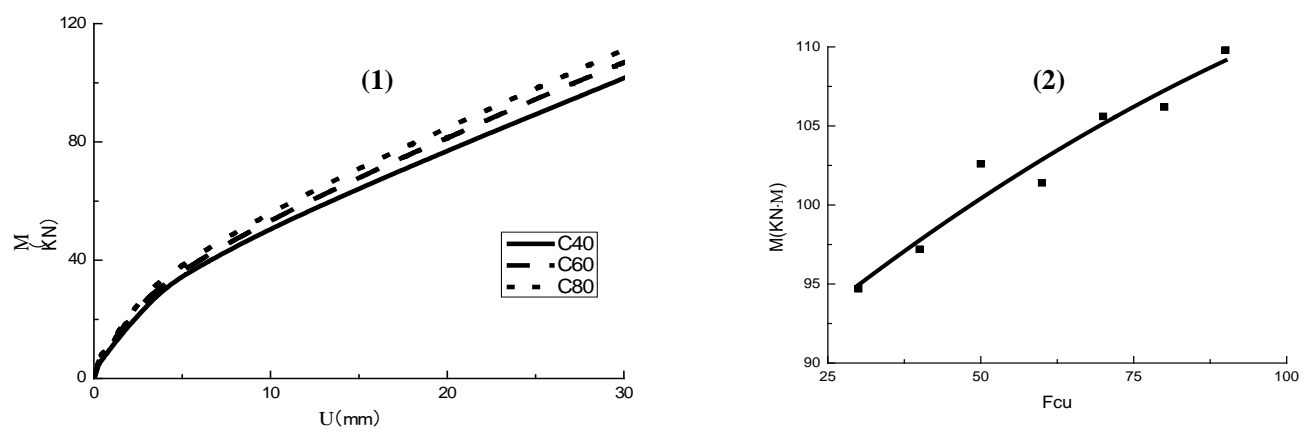

Fig.6 Numerical simulation curve (Effect of concrete strength grade)

\subsection{Effect of steel strength}

The core concrete and steel can be seen as a whole at the beginning of the force because of the bond-slip, high-strength steel makes the whole have a larger initial stiffness and a extended elastic section. Fig.7(1) showed that the elastic limit of the high strength steel is larger than that of the lower strength steel, and it has high bending capacity. Fig.7(2) showed that the bending capacity has an approximate linear growth. 

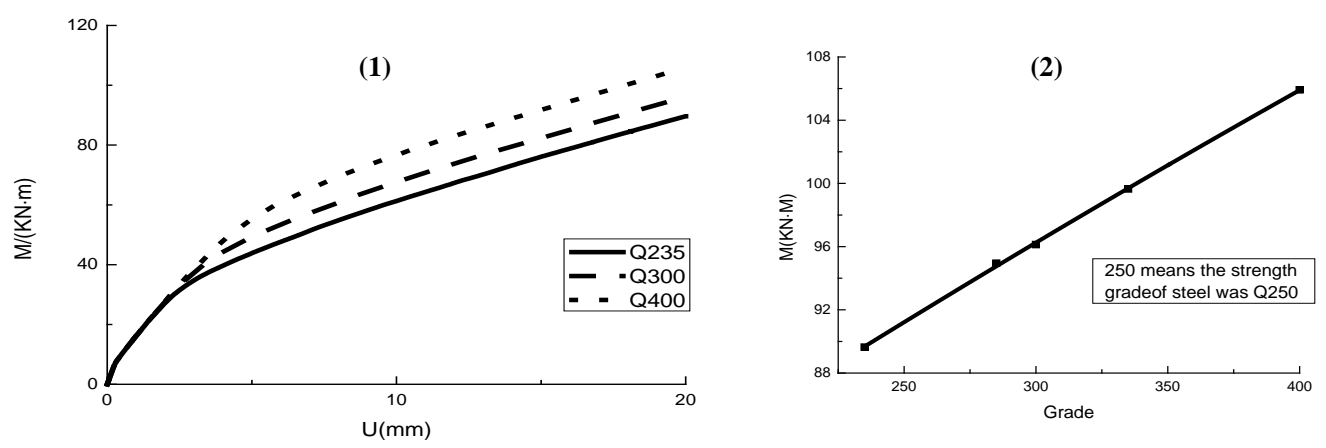

Fig.7 Numerical simulation curve (effect of steel strength)

\subsection{Effect of shear span ratio}

Fig.8(1) showed the effect of shear span ratio was shown. It can be seen from that the effect was a significant on the $\mathrm{M}-\mu$ curve because of shear span ratio. With the increasing of the shear span ratio, the specimen is responsible for its own gravity as well as the same load. The relationship between the bending moment and the length has a quadratic function, and the increase of the bending moment causes the deformation of the composite member and accelerate the bearing capacity decreasing. Fig.8(2) showed the bearing capacity decreasing along with the shear span ratio.
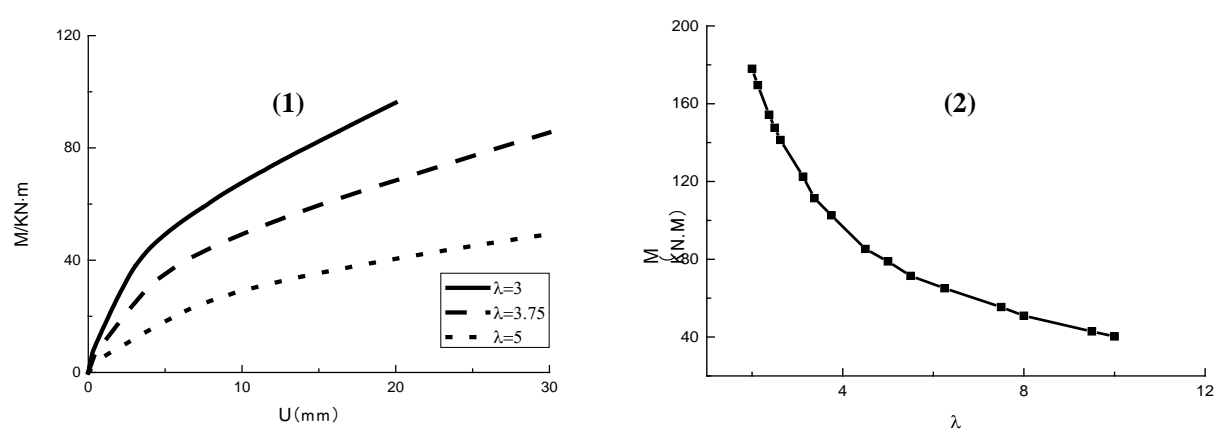

Fig.8 Numerical simulation curve (effect of cut span ratio)

\subsection{Effect of wall thickness}

Fig.9(1) showed the effect of wall thickness. It can be found from Fig. 9(1) that the composite members which one had the thicker GFRP tube had the higher bending capacity, because the thicker GFRP tube can better suppress and the bearing capacity would improve. Fig.9(2) indicate the wall thickened and the bending ability approximated linear growth.
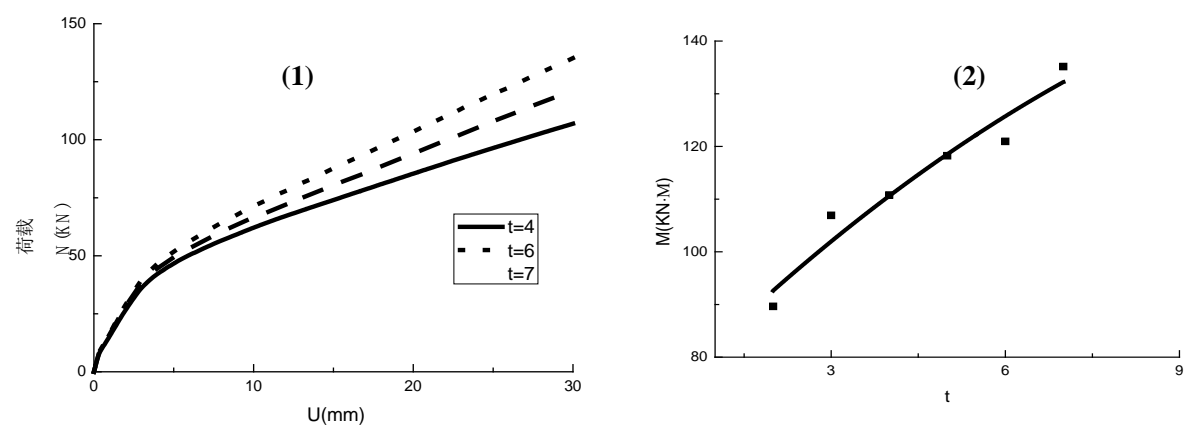

Fig.9 Numerical simulation curve (Effect of GFRP wall thickness) 


\section{Bearing capacity formula simplified calculation}

Based on the unified theory of concrete-filled steel tube[9], the formula for calculating the bending capacity of the combined member was obtained in literature[10], but the attenuation of the bearing capacity caused by the shear ratio of the bending member was not taken into account. In this paper, based on the regression analysis of ABAQUS calculation results and the experimental results, the bearing capacity formula was simplified as follows,

$$
\mathrm{M}=\varphi 0.2821 \mathrm{r}\left(0.89437+1.00010+0.9927 \rho_{\mathrm{s}}\right) \mathrm{A}_{\mathrm{c}} \mathrm{f}_{\mathrm{c}}
$$

$\theta$ means hoop coefficient $\left(\theta=\mathrm{f}_{\mathrm{f}} \mathrm{A}_{\mathrm{f}} / \mathrm{f}_{\mathrm{c}} \mathrm{A}_{\mathrm{c}}, \mathrm{f}_{\mathrm{f}}\right.$ means the circumferential tensile strength of GFRP tube, $\mathrm{A}_{\mathrm{f}}$ means the sectional area of GFRP tube), $\rho_{s}$ means bone index of steel $\left(\rho_{s}=f_{s} A_{f} / f_{c} A_{c}, f_{s}\right.$ means the yield strength of steel, $\mathrm{A}_{\mathrm{s}}$ means the steel cross-sectional area). $\varphi$ means stability factor

$$
\varphi=1-\zeta \sqrt{\frac{L}{D}-4}
$$

where $\zeta$ means shear span ratio reduction factor, L means the calculation span of the beam, D means the outer diameter of the beam.

The reduction coefficient was calculated by changing the shear ratio of the specimen. It can be seen from Fig. 8 that the bending moment in the mid-span decreased with the increase of the shear-span ratio, regression analysis the calculation results and experimental results. We could obtain formula 4:

$$
\left\{\begin{array}{lc}
\zeta=-0.277 \lambda^{2}+1.619 \lambda-1.977 & 2 \leq \lambda \leq 3 \\
\zeta=0.001 \lambda^{2}-0.04 \lambda+0.502 & \lambda>3
\end{array}\right.
$$

In order to verify the applicability and accuracy of the formula of bearing capacity, the experimental data [8] were taken into equation 3 for calculation. The results were shown in table 3 . The results showed that the calculated results are in agreement with the experimental results. The average score of Mcal / Mexp was 1.083 and the mean variance was 0.0125 .

Table 3 Comparison of calculated and experimental values

\begin{tabular}{ccccccl}
\hline $\begin{array}{c}\text { Specimen } \\
\text { number }\end{array}$ & $\lambda$ & $\theta$ & $\rho$ & $\mathrm{M}_{\exp }$ & $\mathrm{M}_{\text {cal }}$ & $\mathrm{M}_{\text {cal }} / \mathrm{M}_{\exp }$ \\
\hline SW1 & 2.2 & 0.7558 & 0.3646 & 65.4 & 70.82 & 1.08 \\
WGSC2 & 3 & 1.0077 & 0.3646 & 72.36 & 79.68 & 1.10 \\
SW3 & 3.3 & 0.6229 & 0.3646 & 61.8 & 66.14 & 1.07 \\
\hline
\end{tabular}

\section{Conclusions}

By using ABAQUS to simulate the bending properties of GFRP concrete composite members, through the contrast analysis of $\mathrm{M}-\mu$ curve, the following conclusions can be drawn:

(1)Through the comparison with the experimental $\mathrm{N}-\mu$ curve, the numerical simulation were in good agreement with the experimental one, the accuracy of the numerical model could be verified.

(2)The influence of GFRP tube wall thickness, concrete strength grade and steel cross section, shear span ratio on the bending capacity of GFRP composite members were analyzed.

(3)Based on the numerical results and the experimental study, by using the unified theory of concrete-filled steel tube to modify the formula of bending capacity under the consideration of shear - span ratio. The formula calculated results are in good agreement with the experimental results.

\section{References}

[1] CAO Pengpeng. Mechanical behavior of steel-encased concrete filled FRP tube column under unidirectional eccentric compression[D].Shenyang Jianzhu University, 2013. (in Chinese)

[2] XIA Yumin. Mechanical Behavior study on GFRP tube filled with reinforced concrete members under eccentric compression [D].Shenyang Jianzhu University, 2011. (in Chinese)

[3] LI Yang. Research on mechanical properties of the reinforced concrete Filled GFRP tube beams[D]. Northeast Petroleum University, 2013. (in Chinese)

[4] ZHANG Ni, WANG Lianguang. Nonlinear analysis of flexural members of GFRP-concrete-steel doubleskin tubular[J]. Steel Construction, 2014,12: 8-12. (in Chinese)

[5] ZHAO Dazhou, WANG Qingxiang, GUAN Ping. Calculation of bearing capacity of eccentrically loaded circular steel columns filled with steel-reinforced high-strength concrete. China Harbour Engineering, 2003, 02: 26-29. (in Chinese) 
[6] Z.Hashin. Failure criteria for unidirectional fiber composites. Journal of Applied Mechanics, 1980, 47(2):329-334.

[7] QIN Guopeng. Mechanical behaviors study on GFRP tube filled with reinforced concrete members. [D]. Northeastern University, 2010. (in Chinese)

[8] QIN Guopeng, WANG Lianguang, Wu Di. Mechanical behavior of flexural members of CFRP tube filled with steel reinforced concrete. Concrete, 2009, 09:59-61. (in Chinese)

[9] ZHONG Shantong. The unified theory of concrete filled steel tube[J]. Journal of Harbin University of Civil Engineering and Architecture, 1994, 06:21-27. (in Chinese)

[10] WANG Lianguang, CHEN Bailing. Steel reinforced concrete-filled glass fiber reinforced polymer or steel tubular structures [M].Shenyang: Liaoning Science and Technology Publishing House, 2013. (in Chinese) 